\title{
A Novel Coronary CT Angiography Score for Patients of ACS
}

Lu Gan and Li Yang*

Department of Radiology, Chinese PLA General Hospital, Beijing, PR China

*Corresponding author: Li Yang, Department of Radiology, Chinese PLA General Hospital, No. 28 Fuxing Rd, Beijing 100853, PR China, Tel: +8601066939564; E-mail: 13805366900@126.com

Rec date: February 01, 2018; Acc date: February 20, 2018; Pub date: February 23, 2018

Copyright: $\odot 2018 \mathrm{Gan}$ L, et al. This is an open-access article distributed under the terms of the creative commons attribution license, which permits unrestricted use, distribution, and reproduction in any medium, provided the original author and source are credited.

\section{Abstract}

Background: Coronary atherosclerosis is one of the most significant diseases in recent years. CCTA can provide a non-invasive quantitative assessment of coronary atherosclerotic plaque.

Objectives: To describe a novel score with CCTA in assessment of coronary atherosclerotic plaque characteristics in patients with acute coronary syndrome (ACS).

Methods: We retrospectively analyzed 213 patients from Jun 2012 to Jun 2014. All patients were classified into four groups: healthy individuals as a control group, unstable angina group (UA), non-ST-segment elevation myocardial infarction group (NSTEMI) and ST-segment elevation myocardial infarction group (STEMI). Segment involvement score (SIS), segment stenosis score (SSS) and a novel CCTA score (CCTAs) were calculated, respectively. All evaluation indicators were analyzed with SPSS 20.0 software. All images were analyzed by two experienced radiologists, they had no knowledge of clinical or angiographic results.

Results: 1. Significant differences were found among all groups of age $(P=0.007)$, SBP $(P=0.013)$, and males $(P=0.047)$. 2. Significant differences in SIS, SSS, CCTAs were found between the UA, NSTEMI and STEMI groups $(P=0.00)$ 3. SBP and CCTAs were found to be independent risk factors of UA $(O R=1.042, P=0.008 ; O R=1.211$, $\mathrm{P}=0.000$, respectively). CCTAs were independent risk factors of $\mathrm{MI}(\mathrm{OR}=1.77, \mathrm{P}=0.000)$. 4. With healthy group as control, for group UA, AUC of CCTAs was 0.741. For group MI, AUC of CCTAs was 0.955 . The efficiency of simultaneously identifying cases (i.e., SBP and CCTAs) in group UA was 0.850 .

Conclusion: CCTAs are more robust than SIS, SSS scores for the diagnoses of patients with ACS.

Keywords: Acute coronary syndrome; Unstable angina; Myocardial infarction; Coronary computer tomography angiography; Coronary angiography

\section{Introduction}

Coronary atherosclerosis is one of the most significant diseases in recent years. Though rates of death attributable to CVD have declined, the burden of the disease remains high [1]. A large percentage of the population has never been diagnosed or experienced typical symptoms of CVDs before MACE [2]. Therefore, the early diagnosis and treatment of ACS is of the utmost importance, especially the development of a non-invasive diagnostic test. CCTA can provide a noninvasive quantitative assessment of total coronary atherosclerotic burden [3]. In patients with chest pain, CCTA identifies increased risks for death. More importantly, a negative CCTA indicates an extremely low risk for death [4]. Multiple studies have shown that coronary artery stenosis can be identified with high sensitivity and specificity by CCTA if the image quality is adequate [5]. In CCTA, both plaque burden and stenosis, particularly in proximal segments, carry incremental prognostic value. A prognostic score on the basis of these data can improve risk prediction beyond clinical risk scores [6]. As well known, ACS involves the rupture of vulnerable plaque. We hypothesized that CCTA, a non-invasive and accurate examination method, may be an optimal tool to identify ACS. However, previous studies have mostly focused on plaque location or burden alone. Therefore, the aim of this study is to describe a new optimal predictive score with CCTA for ACS.

\section{Methods}

\section{Population}

A single medical center analyzed a total of 213 patients from Jun 2012 to Jun 2014, with all patients having underwent CCTA examination within 48 hours after admission. Patients with proven ACS or MI were included. Exclusion criteria were defined as: 1. Patient reported past myocardial infarction or angina, 2. Coronary revascularization (i.e., PCI, stent, and coronary artery bypass grafting), 3. Renal insufficiency, 4. Allergic to iodine, 5. Bad tolerance to CCTA examination, and 6. Pregnant women and minors. The study was approved by the local ethics committee. A detailed medical history was obtained from EMRs of patients to assess for the presence of: 1 . diabetes mellitus (defined as having a fasting glucose level of $>7$ $\mathrm{mmol} / \mathrm{l}$ or the need for insulin or oral hypoglycemic agents); [7] 2. Dyslipidemia (defined as having a total cholesterol level $>5 \mathrm{mmol} / \mathrm{l}$ or treatment with lipid-lowering drugs ;) [8] 3. Hypertension (defined as having a blood pressure of $140 / 90 \mathrm{mmHg}$ or the use of antihypertensive medication); [9] 4. Obesity (having a body mass index $<30 \mathrm{~kg} / \mathrm{m}^{2}$ ); [10] 5. Positive family history of premature CAD 
(defined as the presence of CAD in first-degree relatives younger than 55 (male) or 65 (female) years of age); [11] 6. Smoking (defined as being a previous (less 1 year) or current smoker).

\section{Scan protocol and image reconstruction}

All scans were performed according to SCCT guidelines for the performance of coronary computed tomographic angiography with a multidetector CT scanner (256iCT Philips). During the CCTA angiography acquisition, $60 \mathrm{ml}$ iodinated contrast $(370 \mathrm{mgI} / \mathrm{mlBayer}$ Schering Pharmacy, Deutschland) was injected followed by a $45 \mathrm{ml}$ saline flush. Helical scan data were obtained with retrospective or prospective electrocardiographic gating. Images were reconstructed immediately after the completion of the scan in a consistent manner. Images were reconstructed at $40 \%, 45 \%$, and $78 \%$ of the cardiac cycle.

The optimal phase reconstruction was assessed by a comparison of different phases, and the phase with the least amount of coronary artery motion was chosen for analysis. Multiple phases were used for the image interpretation if minimal coronary artery motion was different for different arteries. The images were evaluated on transaxial 2-dimensional image stacks (raw data), multiplanar reformations (MPRs), maximum intensity projections (MIPs), curved multiplanar reformations (cMPRs), and volume-rendering technique (VRT) reconstructions reviews.

Two orthogonal, thin, maximal intensity projection cardiocentric views approximating traditional coronary angiography angles were used to detect obstructive coronary plaque. Then, arterial segment stenosis and plaque pattern in the narrowest point of every segment were scored and recorded. If a coronary artery segment was uninterpretable, the case was ruled out.

\section{CCTA image analyses}

All images were analyzed by two radiologists with experience interpreting several thousand CCTA scans. They had no knowledge of any diagnoses and angiographic results. In each coronary artery segment, coronary atherosclerosis was defined as the presence of tissue structures $>1 \mathrm{~mm} 2$ that existed either within the coronary artery lumen or adjacent to the coronary artery lumen that could be discriminated from surrounding pericardial tissue, epicardial fat, or the vessel lumen itself. Coronary artery segments were appropriately identified with the use of the 15-segment American Heart Association (AHA) model [12]. In the past, several investigators have noted the presence of more than one vulnerable plaque in patients at risk of cardiovascular events.

However, a more recent series of publications on vulnerability reiterated the importance of going beyond a vulnerable plaque and called for the evaluation of the total arterial tree as a whole [13-17]. In light of these findings, we selected two clinical coronary artery plaque scores which were simple and easy to apply: 1 . segment stenosis score (SSS); and 2. Segment involvement score (SIS). The two semiquantitative measures of coronary plaque burden can be determined with a high degree of inter-observer agreement, suggesting their potential role as tools to aid in the consistent assessment of coronary heart disease $[6,18]$.

Therefore, we used them as tools to aid in assessments of ACS. Taking into account plaque composition, we also constructed a new CCTA score based on the SSS. According to the present, generally adopted criterion [13,19-21], plaque is classified as non-calcified plaque, mixed plaque and calcified plaque [5]. Additional weighting factors are assigned to each classification of plaque to reflect the assumption of less plaque vulnerability of the latter category: 2 to noncalcified plaques, 1.5 to predominantly non-calcified mixed plaques and 1 to predominantly calcified plaques [22]. First, the SSS of stenosis severity per segment were assessed. Segments were graded as normal (i.e., no stenosis) or with a stenosis level of $1 \%-29 \%, 30 \%-49 \%$, $50 \%-69 \%$, or $>70 \%$ by visual semi-quantification, with assignment of scores of $0,1,2,3$, or 4 , respectively. Stenosis was not measured when the vessel diameter was less than $2 \mathrm{~mm}$.

The percent obstruction of coronary artery lumen was based on a comparison of the luminal diameter of the segment exhibiting obstruction to the luminal diameter of the most normal-appearing site immediately proximal to the plaque (Figure 1 ). SSS was calculated with a possible total ranging from 0 to 60 . SIS was calculated as the total number of coronary artery segments exhibiting plaque, irrespective of the degree of luminal stenosis within each segment (0-15 points) [6]. Coronary atherosclerotic lesions were quantified for stenosis by visual estimation. The impact of luminal plaque was evaluated in terms of the resultant maximum percentage of diameter stenosis or percentage of area stenosis [23].

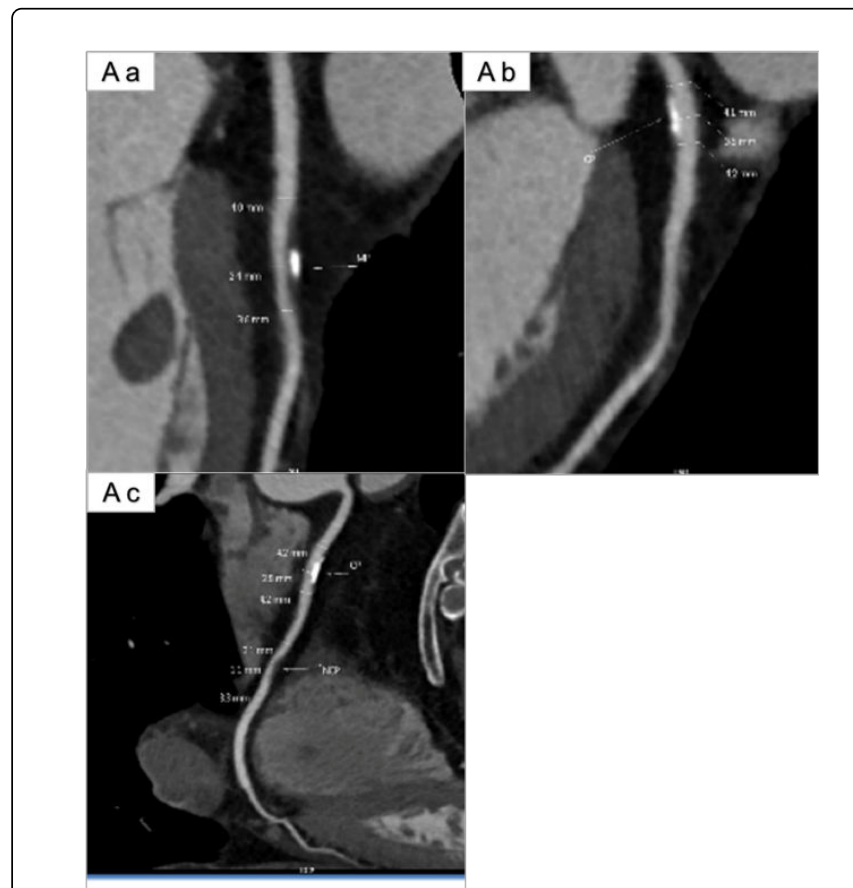

Figure 1: a. SIS $=1, \mathrm{SSS}=1, \mathrm{CCTAs}=1 \times 1 \times 1=1$; b: SIS $=1, \mathrm{SSS}=1$, CCTAs $=1 \times 1 \times 1=1$; c: SIS $=2$, SSS $(\mathrm{CP})=1$, SSS $(\mathrm{NCP})=2$, CCTAs $=1$ $\times 1 \times 1+1 \times 2 \times 2=5$, SIS=4, SSS=5, CCTAs=7.5. CP: calcified plaque, NCP: noncalcified plaque, MP: mixed plaque.

If a plaque was highly calcified, 2-dimensional oblique images were consulted to minimize the partial volume averaging artifact of calcium. CCTAs for each patient was calculated as the sum of each SSS multiplied the weighting factors of plaque composition (calcified plaque-1, mixed plaque-1.5, non-calcified plaque-2; (Figure 1) and (Table 1). In addition, the ACC/AHA score from coronary angiography was recorded. The ACC/AHA score was the sum of all segment scores (each segment score was calculated as the weighting factor multiplied by the severity score). Severity scores were assigned to specific percentage luminal diameter reductions of the coronary 
Citation: Gan L, Yang L (2018) A Novel Coronary CT Angiography Score for Patients of ACS. J Cardiovasc Dis Diagn 6: 309. doi: $10.4172 / 2329-9517.1000309$

Page 3 of 8

artery segment: 4 for $90 \%-100 \%, 3$ for $75 \%-89 \%, 2$ for $50 \%-74 \%, 1$ for $10 \%-49 \%$, and 0 for $<10 \%$. The second diagonal branch, the obtuse marginal, the distal left anterior descending, or the left anterior descending septal perforators with luminal diameters larger than those of any other artery included in the ACC/AHA score replaced the artery with the smallest diameter [24-28]. Two researchers separately calculated the scores without knowing diagnoses of CAG, and the final check was made independently by a third researcher.

\begin{tabular}{|c|c|c|c|c|}
\hline \multicolumn{2}{|l|}{ SIS } & \multirow{2}{*}{$\begin{array}{l}\text { SSS } \\
-3\end{array}$} & \multicolumn{2}{|l|}{ PLAQUE } \\
\hline Segment (1) & Weight (2) & & Classification (4) & Weight (5) \\
\hline RCA-proximal & 1 & 0: normal & calcified & 1 \\
\hline RCA-Mid & 1 & $1:<50 \%$ & mixed & 1.5 \\
\hline RCA-Distal & 1 & 2: $50 \%-75 \%$ & noncalcified & 2 \\
\hline PDA & 1 & $3: \geq 75 \%$ & - & - \\
\hline LM & 1 & - & - & - \\
\hline LAD-proximal & 1 & - & - & - \\
\hline LAD-Mid & 1 & - & - & - \\
\hline LAD-Distal & 1 & - & - & - \\
\hline D1 & 1 & - & - & - \\
\hline D2 & 1 & - & - & - \\
\hline LCX-proximal & 1 & - & - & - \\
\hline LCX-Mid & 1 & - & - & - \\
\hline LCX-Distal & 1 & - & - & - \\
\hline OM1 & 1 & - & - & - \\
\hline OM2 & 1 & - & - & - \\
\hline
\end{tabular}

Table 1: CCTAs $=\sum 【(1) *(2) *(3) *(4) *(5) 】$.

\section{Statistical analysis}

Patient demographic characteristics were presented as means \pm SD or as medians (i.e., interquartile ranges) for continuous variables, and as proportions (i.e., percentages) for categorical variables. Nonparametric Mann-Whitney or Kruskal-Wallis tests were used to compare continuous variables, and the Chi-square test was used to evaluate differences in frequencies. Correlations between CCTAs and CAG (ACC/AHA) scores (CAGs), SSS and CAGs were analyzed with linear correlations. Multivariate analyses (e.g., binary logistic regression model) were performed to identify independent predictors of ACS. Receiver-Operating Characteristic (ROC) curve analyses were used to establish relations between each coronary score of AU and MI. Statistical comparisons were performed with SPSS 20.0 for Windows. Comparisons were considered significant for a two-tailed P-value $<0.05$.

\section{Results}

\section{Baseline information}

From 213 patients, 59\% were men with an average age of $60 \pm 10$ years (range of 36 to 85 years (Table 2). Significant differences were not observed between the groups in the following baseline information: 1 . BMI ( $26 \pm 2.7$ vs. $26.7 \pm 8.2$ vs. $25.8 \pm 3.5$ vs. $25.4 \pm 3.2$; $\mathrm{P}=0.767), 2$. Diabetes mellitus $(20 \%$ vs. $28 \%$ vs. $21 \%$ vs. $36 \% ; \mathrm{P}=0.475), 3$. Hyperlipidemia ( $43 \%$ vs. $28 \%$ vs. $21 \%$ vs. $36 \%$; $\mathrm{P}=0.100$ ), 4 . Family history ( $17 \%$ vs. $28 \%$ vs. $50 \%$ vs. $45 \%$; $\mathrm{P}=0.074), 5$. Smoking ( $26 \%$ vs. $27 \%$ vs. $46 \%$ vs. $45 \%$; $\mathrm{P}=0.155)$, hypertension ( $48 \%$ vs. $66 \%$ vs. $67 \%$ vs. $46 \%$; $\mathrm{P}=0.062$ ), 6. Heart rate ( $76 \pm 7$ vs. $74 \pm 12$ vs. $81 \pm 21$ vs. $76 \pm 13$; $\mathrm{P}=0.113), 7$. $\mathrm{DBP}(79 \pm 9$ vs. $77 \pm 11$ vs. $76 \pm 11$ vs. $73 \pm 12$; $\mathrm{P}=0.200)$.

There were significant differences in age ( $60 \pm 8$ vs. $62 \pm 10$ vs. $55 \pm$ 14 vs. $59 \pm 12 ; \mathrm{P}=0.007)$, $\mathrm{SBP}(127 \pm 19$ vs. $137 \pm 19$ vs. $130 \pm 15$ vs. $130 \pm 16 ; \mathrm{P}=0.013$ ), and male ( $56 \%$ vs. $54 \%$ vs. $84 \%$ vs. $88 \%$; $\mathrm{P}=0.047$ ). Patients in group UA were significantly older than those in group NSTEMI $(\mathrm{P}=0.019)$.

There were slightly but significantly greater frequencies of males in group NSTEMI and STEMI than those in control group and group UA; this may reflect the fact that males are more likely to develop NSTEMI and STEMI than females. Group UA had the highest SBP among the four groups $(\mathrm{P}=0.004)$. 
Citation: Gan L, Yang L (2018) A Novel Coronary CT Angiography Score for Patients of ACS. J Cardiovasc Dis Diagn 6: 309. doi: 10.4172/2329-9517.1000309

Page 4 of 8

\begin{tabular}{|l|l|l|l|l|l|}
\hline Variables & UA & NSTEMI & STEMI & TOTAL \\
\hline N & 89 & 24 & 11 & 213 \\
\hline Age & $62 \pm 10^{*}$ & $54 \%$ & $55 \pm 14^{*}$ & $59 \pm 12$ & $60 \pm 10$ \\
\hline Male & $26.7 \pm 8.2$ & $84 \%$ & $88 \%$ & $59 \%$ & 0.007 \\
\hline BMI & $28 \%$ & $25.8 \pm 3.5$ & $25.4 \pm 3.2$ & $26.3 \pm 5.7$ \\
\hline Diabetes & $28 \%$ & $21 \%$ & $36 \%$ & $24 \%$ & 0.047 \\
\hline Hyperlipidemia & $28 \%$ & $21 \%$ & $36 \%$ & $34 \%$ & 0.475 \\
\hline Family history & $27 \%$ & $50 \%$ & $45 \%$ & $26 \%$ & 0.1 \\
\hline Smoking & $66 \%$ & $46 \%$ & $45 \%$ & $30 \%$ & 0.074 \\
\hline Hypertension & $74 \pm 12$ & $67 \%$ & $46 \%$ & $58 \%$ \\
\hline Heart rate & $137 \pm 19 \$$ & $81 \pm 21$ & $76 \pm 13$ & $76 \pm 12$ \\
\hline SBP & $77 \pm 11$ & $130 \pm 15$ & $130 \pm 16$ & $132 \pm 19$ \\
\hline DBP & $76 \pm 11$ & $73 \pm 12$ & $77 \pm 10$ \\
\hline *: group NSTEMI was younger than group UA, P=0.019. \$: SBP was higher in group UA than in control group, P=0.004. & 0.155 \\
\hline
\end{tabular}

Table 2: Baseline information.

\section{Quantitative image analysis in CCTA and CAG}

In the final study population of 213 patients, 2,358 coronary segments were evaluated. CAGs $(6.6 \pm 5.4$ vs. $8.3 \pm 5.2$ vs. $6.7 \pm 4.3$; $\mathrm{P}=0.557)$ was not significantly different among the groups. SIS, SSS were evaluated according to CCTA images of each patient. Then, CCTAs of the four groups were calculated (i.e., the sum of the SSS multiplied by plaque composition weight factors). Significant differences were found among the control, UA and NSTEMI groups. Furthermore, the scores increased according to group: 1. SIS: $1.6 \pm 2$ vs. $3.2 \pm 2.9$ vs. $5.8 \pm 3.3$ vs. $6.4 \pm 3.3(\mathrm{P}=0)$; 2 . SSS: $1.4 \pm 2$ vs. $5.2 \pm 5.7$ vs. $11 \pm 6.9$ vs. $13.7 \pm 9.7(\mathrm{P}=0)$; and 3 . CCTAs: $2.4 \pm 3.1$ vs. $8.4 \pm 8.8$ vs. $18.5 \pm 10$ vs. $21.5 \pm 12.6(\mathrm{P}=0)$. The three scores in the STEMI group exceeded those in the NSTEMI group, but the differences were not statistically significant $(\mathrm{P}=0.997,0.97$, and 0.986$)$, so we combined groups NSTEMI and STEMI into the MI group for the following analysis (Table 3).

\begin{tabular}{|l|l|l|l|l|l|l|}
\hline Variables & Control & UA & NSTEMI & STEMI & TOTAL & $\mathbf{P}$ \\
\hline SIS & $1.6 \pm 2$ & $3.2 \pm 2.9$ & $5.8 \pm 3.3$ & $6.4 \pm 3.3$ & $2.9 \pm 3$ & 0 \\
\cline { 1 - 6 } TSS & $1.4 \pm 2$ & $5.2 \pm 5.7$ & $11 \pm 6.9$ & $\begin{array}{l}13.7 \quad \pm \\
9.7\end{array}$ & $4.7 \pm 6.2$ & 0 \\
\cline { 1 - 5 } CCTAs & $2.4 \pm 3.1$ & $8.4 \pm 8.8$ & $18.5 \pm 10$ & $\begin{array}{l}21.5 \quad \pm \\
12.6\end{array}$ & $7.7 \pm 9.5$ & 0 \\
\cline { 1 - 5 } $\begin{array}{l}\text { AHA/ACC } \\
\text { Score }\end{array}$ & ----- & $6.6 \pm 5.4$ & $8.3 \pm 5.2$ & $6.7 \pm 4.3$ & $7.1 \pm 5.1$ & 0.557 \\
\cline { 2 - 5 } & & $(\mathrm{N}=27)$ & $(\mathrm{N}=15)$ & $(\mathrm{N}=9)$ & $(\mathrm{N}=51)$ & \\
\hline
\end{tabular}

Table 3: CCTA and CAG score.

\section{Logistic regression analysis of group UA and MI}

After adjusting for several possible difficult variables with multivariable logistic regressions (i.e. age, gender, HR, BMI, DBP, DMs, hypertension, dyslipidaemia, smoking, SIS, SSS etc.) SBP and CCTAs were identified as independent risk factors of UA $(\mathrm{OR}=1.042$, $\mathrm{P}=0.008, \quad 95 \% \quad \mathrm{CI}: 1.011-1.074 ; \quad \mathrm{OR}=1.211, \quad \mathrm{P}=0.000, \quad 95 \% \quad \mathrm{CI}$ : 1.090-1.345, respectively) and CCTAs were independent of the risk factors of MI (OR=1.77, $\mathrm{P}=0.000,95 \% \mathrm{CI}: 1.332-2.352)$, as indicated by the Hosmer and Lemeshow tests: $\mathrm{P}=0.901$ and 0.941 , respectively (Tables 4 and 5).

\begin{tabular}{|l|l|l|l|l|l|l|l|}
\hline Variables & B & S.E. & Wals & Sig. & $\operatorname{Exp(B)}$ & $\mathbf{9 5 \%}$ Cl & - \\
\hline CCTAs & 0.648 & 0.221 & 8.583 & 0.003 & 1.911 & 1.239 & 2.947 \\
\hline Constant & -4.782 & 8.793 & 0.296 & 0.587 & 0.008 & - & - \\
\hline
\end{tabular}

Table 4: Group MI.

\begin{tabular}{|c|c|c|c|c|c|c|c|}
\hline Variables & B & S.E. & Wals & Sig. & $\operatorname{Exp(B)}$ & $\mathbf{9 5 \%}$ CI & - \\
\hline SBP & 0.041 & 0.015 & 7.116 & 0.008 & 1.042 & 1.011 & 1.074 \\
\hline CCTAs & 0.191 & 0.054 & 12.682 & 0 & 1.211 & 1.09 & 1.345 \\
\hline Constant & 0.959 & 2.809 & 0.116 & 0.733 & 2.608 & - & - \\
\hline
\end{tabular}

Table 5: Group UA.

\section{ROC of SIS, SSS, CCTAs in UA and MI groups}

Using the control group as the ROC control group, the AUCs of SIS, SSS and CCTAs in the UA group were 0.691, 0.744, and 0.741, respectively $(\mathrm{P}=0.000)$. The optimal cut-off points were 2,2 , and 3 , respectively, and the corresponding sensitivities and specificities were 
Page 5 of 8

$62.5 \%, 71.9 \%$, and $69.7 \%$ and $61.8 \%, 67.4 \%$, and $68.5 \%$. The AUCs of SIS, SSS and CCTAs in the MI group were $0.878,0.946$, and 0.955 , respectively, and the optimal cut-off points were 4,5 , and 5.5 . The corresponding sensitivities and specificities were $74.3 \%, 85.7 \%$, and $94.3 \%$ and $84.3 \%, 92.1 \%$, and $86.5 \%$, respectively.

\section{Linear correlation analysis between CCTAs and CAGs}

Linear correlation analyses showed that moderate positive correlations existed between CCTAs and CAGs in the UA $(\mathrm{P}=0)$, NSTEMI $(\mathrm{P}=0.002)$ and STEMI $(\mathrm{P}=0.023)$ groups. The correlation coefficients were $0.739,0.747$ and 0.653 , respectively. Strong positive correlations were also found between CCTAs and SSS in the control, UA, NSTEMI and STEMI groups $(\mathrm{P}=0)$. The correlation coefficients were $0.965,0.958,0.953$ and 0.985 , respectively. A moderate positive correlation existed between SSS and CAGs in the UA $(\mathrm{P}=0)$, NSTEMI $(\mathrm{P}=0.003)$ and STEMI $(\mathrm{P}=0.025)$ groups. The correlation coefficients were $0.635,0.714$ and 0.731 , respectively.

\section{Discussion}

In the present study, we observed the predictive value of CCTAs for patients with ACS, built a novel score of CCTA and conducted a conventional CHD risk factor analysis for UA.

\section{Predicted values of SIS and SSS}

There are a number of non-invasive and invasive imaging techniques available for the diagnosis of coronary plaque burden, including invasive coronary angiography (ICA), single-photon emission computed tomography (SPECT) myocardial perfusion imaging (MPI), exercise ECG treadmill test (ETT), stress echocardiography (ECHO) and coronary computed tomography angiography (CCTA). The sensitivity and specificity of each test is described in Table 6. ICA plays a central role in the management of patients with coronary artery disease (CAD) and is currently the standard for confirming the presence of athermanous coronary obstructions. However, in addition to its high cost and radiation exposure, it is not necessary for all patients showing symptoms of CAD $[29,30]$.

CCTA may also provide accurate and sufficient information about the presence of extra-luminal plaque and plaque composition not routinely available using ICA [31-38]. Cardiac CTA shares similar elements with echocardiography and thoracic radiology in addition to the properties of ICA [23]. In patients undergoing CCTA, both atherosclerotic plaque burden and obstructive coronary diseased particularly in the proximal segments carry incremental prognostic value beyond clinical risk factors [6]. Hence, CCTA would be a validated and convenient way for the prediction of ACS. A study of the ability for CCTA in predicting acute coronary syndrome for cardiovascular risk models and coronary atherosclerotic plaque showed that the median number of coronary segments (SIS) with atherosclerotic plaque was higher in subjects with ACS compared with those without $\mathrm{ACS}(8, \mathrm{IQR}=4$ to 10 vs. $0, \mathrm{IQR}=0$ to $3 ; \mathrm{p}<0.001)$ [39].

The results from a multicenter international CONFIRM registry revealed that the SIS and SSS of CAD by CCTA added an incremental discriminatory value to identify individuals at risk of death or MI over models incorporating only clinical CAD risk factors [40]. Our present results were in accordance with this study. Furthermore, our study expands on previous literature by confirming that SIS and SSS have differential diagnostic values in patients with UA and MI, and we also determined the optimal cut-off value (2, 2 and 4, 5, respectively) of SIS and SSS for both diseases.

\begin{tabular}{|c|c|c|}
\hline TESE & Sensitivity & Specificity \\
\hline Exercise ECG treadmill [41] & $68 \%$ & $77 \%$ \\
\hline Exercise echocardiography treadmill [42] & $86 \%$ & $81 \%$ \\
\hline Dobutamine echocardiography [42] & $85 \%$ & $85 \%$ \\
\hline Exercise nuclear treadmill [43] & $87 \%$ & $73 \%$ \\
\hline Pharmacology nuclear testing [43] & $89 \%$ & $75 \%$ \\
\hline Coronary CT angiography [44] & $95 \%$ & $83 \%$ \\
\hline
\end{tabular}

Table 6: The sensitivity and specificity of each test.

\section{Predictive value of CCTAs}

CCTAs include information on the extent, severity and composition of plaque. With regard to plaque composition, CCTA permits the assessment of coronary atherosclerotic plaque morphology and composition in good agreement with intravascular ultrasound $[45,46]$. We found that non-calcified plaque, with a higher weight factor in CCTAs, more frequently occurred in UA and NSTEMI groups; this observation is consistent with previous studies. Non-calcified plaque is often considered more vulnerable to future ruptures and hence, angina, acute myocardial infarction and death [19-21,37,47,48].

In the present study, the plaque composition, extent and severity of stenosis were comprehensively reflected by CCTAs. The score was statistically significant with CAGs score.

With respect to the prediction of UA and MI, it had a larger area under the ROC than those of SIS and SSS. However, the sensitivities and specificities were lower than those in Yuichi's study, in which ACS was defined by having coronary artery stenosis $\geq 75 \%$, low-density plaques, and/or myocardial perfusion defects. The sensitivity and specificity of MSCT to identify ACS were $95.5 \%$ and $88.9 \%$, respectively [49]. We believe that the high threshold, while improving the sensitivity and specificity of study, was not suitable for mild-tomoderate segment stenosis. The recommended threshold of SIS, SSS and CCTAs were 2, 2, and 3 and 4, 5, and 5.5, respectively, for UA and MI according to our study.

Chest pains in the multivariable analysis did not change the predictive power of CCTA; therefore, we ignored chest pains in our analyses $[3,33]$.

\section{Conclusion}

The novel CCTAs for the prediction of ACS is feasible and convenient. CCTAs are more robust than SIS, SSS scores for the diagnoses of patients with ACS.

\section{Limitation}

1. In our retrospective study, a conventional CT plaque classification scheme with an average diagnostic accuracy of $61 \%$ was used in the calculation of CCTAs. Its ability to distinguish individual plaques that may be at higher risk for cardiovascular events was limited [45,46,50-52]. To date, a new classification of plaque composition (e.g., calcified plaque, homogenous plaque, non-napkin-ring signed plaque 
and napkin-ring signed plaque) has been proven to have higher sensitivity and specificity [22]. We will consider adopting it in a future study. 2. Several intravascular ultrasound (IVUS) and CCTA studies have proven to have significantly higher frequencies and greater degrees of positive remodeling in ACS [53,54]. In following studies, we will focus on both IVUS and CCTA by using semi-quantitative analysis software. 3. Coronary calcium scoring (CCS) was not analyzed in our study. Generally, calcium scoring computer programs identify pixels exceeding 130 Hounsfield units as a calcium level corresponding to triggering a non-contrast study [55,56]. Because the dose of contrast media, the scoring algorithm, the disturbance from moving artifacts, partial volume effects, and the presence of metal density foreign bodies vary with scan conditions, CCS often yields inaccurate results [57-59].

In addition, a zero-calcium score does not necessarily guarantee the absence of significant CAD, even in patients older than 60 years of Asian ethnicity presenting with chest pain [60]. Thus, we abandoned CCS. 4. Total coronary occlusion was not separated from high grade stenosis $(\geq 70 \%)$ in our study. To our knowledge, chronic total occlusion and especially acute occlusion, are caused by ruptured vulnerable plaques and subsequent thrombosis [61]. A group of Japanese scholars reported that a 64-slice CT could accurately and non-invasively evaluate image characteristics in coronary artery culprit-lesions in ACS subjects but could not differentiate soft plaques from fibrotic plaques and thrombi generated by plaque rupture [62].

Our focus in this study was not thrombus, but atherosclerosis plaque. Thus, the total occlusion was classified as high-grade stenosis $(\geq 70 \%)$. 5. In our clinical practice, the use of direct invasive treatment without CCTA examination in a high-risk patient was unfavorable to our study. This resulted in significantly smaller sizes of NSTEMI and STEMI groups than that of the UA group, which affected the veracity and objectivity of the result.

In conclusion, the assessment of coronary atherosclerosis with CCTA for the prediction of ACS is feasible and convenient. A novel CCTA was set up to distinguish the UA group from the control group, which is a comprehensive, innovative and valuable tool and is more reliable than SIS, SSS and CAGs for the diagnosis of patients with ACS.

\section{Conflict of Interest}

The authors declare that there are no conflicts.

\section{Acknowledgement}

This research was supported by the National Natural Science Foundation of China (Grant number: 81371547).

\section{References}

1. Go AS, Mozaffarian D, Roger VL, Benjamin EJ, Berry JD, et al. (2014) Executive summary: Heart disease and stroke statistics--2014 update: A report from the American Heart Association. Circulation 129: 399-410.

2. Myerburg RJ, Interian A Jr, Mitrani RM, Kessler KM, Castellanos A (1997) Frequency of sudden cardiac death and profiles of risk. Am J Cardiol 80: 10f-19f.

3. Chow BJ, Small G, Yam Y, Chen L, Achenbach S, et al. (2011) Incremental prognostic value of cardiac computed tomography in coronary artery disease using CONFIRM: COroNary computed tomography angiography evaluation for clinical outcomes: An international multicenter registry. Circ Cardiovasc Imaging 4: 463-472.

4. Min JK, Shaw LJ, Devereux RB, Okin PM, Weinsaft JW, et al. (2007) Prognostic value of multidetector coronary computed tomographic angiography for prediction of all-cause mortality. J Am Coll Cardiol 50: 1161-1170.

5. Abbara S, Arbab-Zadeh A, Callister TQ, Desai MY, Mamuya W, et al. (2009) SCCT guidelines for performance of coronary computed tomographic angiography: a report of the Society of Cardiovascular Computed Tomography Guidelines Committee. J Cardiovasc Comput Tomogr 3: 190-204.

6. Hadamitzky M, Achenbach S, Al-Mallah M, Berman D, Budoff M, et al. (2013) Optimized prognostic score for coronary computed tomographic angiography: results from the CONFIRM registry (Coronary CT Angiography Evaluation for Clinical Outcomes: An International Multicenter Registry). J Am Coll Cardiol 62: 468-476.

7. Report of the expert committee on the diagnosis and classification of diabetes mellitus. Diabetes care 26: S5-S20.

8. NCEP (2001) Executive summary of the third report of the national cholesterol education program (NCEP) expert panel on detection, evaluation, and treatment of high blood cholesterol in adults (adult treatment panel III). JAMA 285: 2486-2497.

9. Mancia G, Fagard R, Narkiewicz K, Redon J, Zanchetti A, et al. (2013) 2013 ESH/ESC Guidelines for the management of arterial hypertension: The task force for the management of arterial hypertension of the European Society of Hypertension (ESH) and of the European Society of Cardiology (ESC). J Hypertension 31: 1281-1357.

10. Jensen MD, Ryan DH, Donato KA, Apovian CM, Ard JD, et al. (2014) Executive summary: Guidelines (2013) for the management of overweight and obesity in adults: A Report of the American College of Cardiology/American Heart Association Task Force on Practice Guidelines and The Obesity Society Published by The Obesity Society and American College of Cardiology/American Heart Association Task Force on Practice Guidelines. Based on a systematic review from the The Obesity Expert Panel, 2013. Obesity 22: S5-S39.

11. Taylor AJ, Bindeman J, Feuerstein I, Cao F, Brazaitis M, et al. (2005) Coronary calcium independently predicts incident premature coronary heart disease over measured cardiovascular risk factors: mean three-year outcomes in the Prospective Army Coronary Calcium (PACC) project. J Am Coll Cardiol 46: 807-814.

12. Austen WG, Edwards JE, Frye RL, Gensini GG, Gott VL, et al. (1975) A reporting system on patients evaluated for coronary artery disease. Report of the Ad Hoc Committee for Grading of Coronary Artery Disease, Council on Cardiovascular Surgery, American Heart Association. Circulation 51: 5-40.

13. Pasterkamp G, Vink A, Borst C (2001) Multiple complex coronary plaques in patients with acute myocardial infarction. $\mathrm{N}$ Engl J Med 344: 527-528.

14. Haft JI (2003) Multiple atherosclerotic plaque rupture in acute coronary syndrome. Circulation 107: e65-e66.

15. Russell CJ, Exley AR, Ritchie AJ (2003) Widespread coronary inflammation in unstable angina. N Engl J Med 348: 1931.

16. Casscells W, Naghavi M, Willerson JT (2003) Vulnerable atherosclerotic plaque: a multifocal disease. Circulation 107: 2072-2075.

17. Maseri A, Fuster V (2003) Is there a vulnerable plaque? Circulation 107: 2068-2071.

18. Pagali SR, Madaj P, Gupta M, Nair S, Hamirani YS, et al. (2010) Interobserver variations of plaque severity score and segment stenosis score in coronary arteries using 64 slice multidetector computed tomography: a substudy of the ACCURACY trial. J Cardiovasc Comput Tomogr 4: 312-318.

19. Virmani R, Kolodgie FD, Burke AP, Farb A, Schwartz SM (2000) Lessons from sudden coronary death: A comprehensive morphological classification scheme for atherosclerotic lesions. Arterioscler Thromb Vasc Biol 20: 1262-1275.

20. Naghavi M, Libby P, Falk E, Casscells SW, Litovsky S, et al. (2003) From vulnerable plaque to vulnerable patient: a call for new definitions and risk assessment strategies: Part II. Circulation 108: 1772-1778. 
21. Naghavi M, Libby P, Falk E, Casscells SW, Litovsky S, et al. (2003) From vulnerable plaque to vulnerable patient: a call for new definitions and risk assessment strategies: Part I. Circulation 108: 1664-1672.

22. Maurovich-Horvat P, Schlett CL, Alkadhi H, Nakano M, Otsuka F, et al. (2012) The napkin-ring sign indicates advanced atherosclerotic lesions in coronary CT angiography. JACC Cardiovasc Imaging 5: 1243-1252.

23. Raff GL, Abidov A, Achenbach S, Berman DS, Boxt LM, et al. (2009) SCCT guidelines for the interpretation and reporting of coronary computed tomographic angiography. J Cardiovasc Comput Tomogr 3: 122-136.

24. Huang G, Zhao JL, Du H, Lan XB, Yin YH (2010) Coronary score adds prognostic information for patients with acute coronary syndrome. Circ J 74: 490-495.

25. Asimakopoulos G, Al-Ruzzeh S, Ambler G, Omar RZ, Punjabi P, et al. (2003) An evaluation of existing risk stratification models as a tool for comparison of surgical performances for coronary artery bypass grafting between institutions. Eur J Cardiothorac Surg 23: 935-941.

26. Guidelines for coronary angiography (1987) A report of the American College of Cardiology/American Heart Association Task Force on Assessment of Diagnostic and Therapeutic Cardiovascular Procedures (Subcommittee on Coronary Angiography). Circulation 76: 963a-977a.

27. Spears JR, Sandor T, Als AV, Malagold M, Markis JE, et al. (1983) Computerized image analysis for quantitative measurement of vessel diameter from cineangiograms. Circulation 68: 453-461.

28. Eigler N, Pfaff JM, Whiting J, Nivatpumin T, Forrester JS (1986) The role of digital angiography in the evaluation of coronary artery disease. Int $\mathrm{J}$ Cardiol 10: 3-13.

29. Antman EM, Cohen M, Bernink PJ, McCabe CH, Horacek T, et al. (2000) The TIMI risk score for unstable angina/non-ST elevation MI: A method for prognostication and therapeutic decision making. JAMA 284: 835-842.

30. Diamond GA, Kaul S (2010) Low diagnostic yield of elective coronary angiography. N Engl J Med 363: 93.

31. Zeb I, Abbas N, Nasir K, Budoff MJ (2014) Coronary computed tomography as a cost-effective test strategy for coronary artery disease assessment - a systematic review. Atherosclerosis 234: 426-435.

32. Goldstein JA, Chinnaiyan KM, Abidov A, Achenbach S, Berman DS, et al. (2011) The CT-STAT (Coronary Computed Tomographic Angiography for Systematic Triage of Acute Chest Pain Patients to Treatment) trial. J Am Coll Cardiol 58: 1414-1422.

33. Litt HI, Gatsonis C, Snyder B, Singh H, Miller CD, et al. (2012) CT angiography for safe discharge of patients with possible acute coronary syndromes. N Engl J Med 366: 1393-1403.

34. Hoffmann U, Truong QA, Fleg JL, Goehler A, Gazelle S, et al. (2012) Design of the Rule Out Myocardial Ischemia/Infarction Using Computer Assisted Tomography: a multicenter randomized comparative effectiveness trial of cardiac computed tomography versus alternative triage strategies in patients with acute chest pain in the emergency department. Am Heart J 163: 330-338.e1.

35. Henzler T, Gruettner J, Meyer M, Rothhaar B, Apfaltrer P, et al. (2013) Coronary computed tomography and triple rule out $\mathrm{CT}$ in patients with acute chest pain and an intermediate cardiac risk for acute coronary syndrome: part 2: economic aspects. Eur J Radiol 82: 106-111.

36. Hoffmann U, Moselewski F, Nieman K, Jang IK, Ferencik M, et al. (2006) Noninvasive assessment of plaque morphology and composition in culprit and stable lesions in acute coronary syndrome and stable lesions in stable angina by multidetector computed tomography. J Am Coll Cardiol 47: 1655-1662.

37. Schmid M, Pflederer T, Jang IK, Ropers D, Sei K, et al. (2008) Relationship between degree of remodeling and CT attenuation of plaque in coronary atherosclerotic lesions: an in-vivo analysis by multi-detector computed tomography. Atherosclerosis 197: 457-464.

38. Ayaram D, Bellolio MF, Murad MH, Laack TA, Sadosty AT, et al. (2013) Triple rule-out computed tomographic angiography for chest pain: a diagnostic systematic review and meta-analysis. Acad Emerg Med 20: 861-871.
39. Ferencik M, Schlett CL, Bamberg F, Truong QA, Nichols JH, et al. (2012) Comparison of traditional cardiovascular risk models and coronary atherosclerotic plaque as detected by computed tomography for prediction of acute coronary syndrome in patients with acute chest pain. Acad Emerg Med 19: 934-942.

40. Al-Mallah MH, Qureshi W, Lin FY, Achenbach S, Berman DS, et al. (2014) Does coronary CT angiography improve risk stratification over coronary calcium scoring in symptomatic patients with suspected coronary artery disease? Results from the prospective multicenter international CONFIRM registry. Eur Heart J Cardiovasc Imaging 15: 267-274.

41. ACC/AHA 2002 guideline update for exercise testing: summary article. J Am Coll Cardiol 40: 1531e40.

42. ACC/AHA/ASE 2003 guideline update for the clinical application of echocardiography. J Am Coll Cardiol 42: 954e70.

43. ACC/AHA/ASNC guidelines for the clinical use of cardiac radionuclide imaging (2003). J Am Coll Cardiol 42: 1318e33.

44. ACCURACY Study (2008). J Am Coll Cardiol 52: 1724e32.

45. Achenbach S, Raggi P (2010) Imaging of coronary atherosclerosis by computed tomography. Eur Heart J 31: 1442-1448.

46. Becker CR, Knez A, Ohnesorge B, Schoepf UJ, Reiser MF (2000) Imaging of noncalcified coronary plaques using helical CT with retrospective ECG gating. Am J Roentgenol 175: 423-424.

47. Navaravong L, Steenson C, Sigurdsson G (2014) Coronary plaque type and burden by computed tomography angiography without association to C-reactive protein. North Am J Med Sci 6: 260-265.

48. Inoue F, Sato Y, Matsumoto N, Tani S, Uchiyama T (2004) Evaluation of plaque texture by means of multislice computed tomography in patients with acute coronary syndrome and stable angina. Circ J 68: 840-844.

49. Sato Y, Matsumoto N, Ichikawa M, Kunimasa T, Iida K, et al. (2005) Efficacy of multislice computed tomography for the detection of acute coronary syndrome in the emergency department. Circ J 69: 1047-1051.

50. Becker CR, Nikolaou K, Muders M, Babaryka G, Crispin A, et al. (2003) Ex vivo coronary atherosclerotic plaque characterization with multidetector-row CT. Eur Radiol 13: 2094-2098.

51. Obaid DR, Calvert PA, Gopalan D, Parker RA, West NE, et al. (2014) Dual-energy computed tomography imaging to determine atherosclerotic plaque composition: A prospective study with tissue validation. J Cardiovasc Comput Tomogr 8: 230-237.

52. Ferencik M, Chan RC, Achenbach S, Lisauskas JB, Houser SL, et al (2006) Arterial wall imaging: evaluation with 16-section multidetector $\mathrm{CT}$ in blood vessel phantoms and ex vivo coronary arteries. Radiology 240: 708-716.

53. Nakamura M, Nishikawa $H$, Mukai S, Setsuda M, Nakajima $K$, et al. (2001) Impact of coronary artery remodeling on clinical presentation of coronary artery disease: an intravascular ultrasound study. J Am Coll Cardiol 37: 63-69.

54. Kalra DK, Heo R, Valenti V, Nakazato R, Min JK (2014) Role of computed tomography for diagnosis and risk stratification of patients with suspected or known coronary artery disease. Arterioscler Thromb Vasc Biol 34: 1144-1154.

55. Agatston AS, Janowitz WR, Hildner FJ, Zusmer NR, Viamonte M Jr, et al. (1990) Quantification of coronary artery calcium using ultrafast computed tomography. J Am Coll Cardiol 15: 827-832.

56. Simons DB, Schwartz RS, Edwards WD, Sheedy PF, Breen JF, et al. (1992) Noninvasive definition of anatomic coronary artery disease by ultrafast computed tomographic scanning: a quantitative pathologic comparison study. J Am Coll Cardiol 20: 1118-1126.

57. Rutten A, Isgum I, Prokop M (2008) Coronary calcification: effect of small variation of scan starting position on Agatston, volume, and mass scores. Radiology 246: 90-98.

58. Hong C, Becker CR, Schoepf UJ, Ohnesorge B, Bruening R, et al. (2002) Coronary artery calcium: absolute quantification in nonenhanced and contrast-enhanced multi-detector row CT studies. Radiology 223: 474-480. 
Citation: Gan L, Yang L (2018) A Novel Coronary CT Angiography Score for Patients of ACS. J Cardiovasc Dis Diagn 6: 309. doi: 10.4172/2329-9517.1000309

Page 8 of 8

59. Rumberger JA, Kaufman L (2003) A rosetta stone for coronary calcium risk stratification: agatston, volume, and mass scores in 11,490 individuals. Am J Roentgenol 181: 743-748.

60. Yoon YE, Chang SA, Choi SI, Chun EJ, Cho YS, et al. (2012) The absence of coronary artery calcification does not rule out the presence of significant coronary artery disease in Asian patients with acute chest pain. Int J Cardiovasc Imaging 28: 389-398.

61. Garcia-Tejada J, Jurado-Roman A, Rodriguez J, Velazquez M, Hernandez F, et al. (2014) Post-resuscitation electrocardiograms, acute coronary findings and in-hospital prognosis of survivors of out-of-hospital cardiac arrest. Resuscitation 85: 1245-1250.

62. Takaoka H, Ishibashi I, Uehara M, Rubin GD, Komuro I, et al. (2012) Comparison of image characteristics of plaques in culprit coronary arteries by 64 slice CT and intravascular ultrasound in acute coronary syndromes. Int J Cardiol 160: 119-126. 